International Journal of Maternal and Child Health and AIDS (20I8), Volume 8, Issue 2, I56-I 62

\begin{tabular}{ll}
\hline & INTERNATIONAL JOURNAL of \\
& MATERNAL and CHILD HEALTH and AIDS \\
& ISSN 216I-864X (Online) \\
& ISSN 216I-8674 (Print) \\
IJMA Available online at www.mchandaids.org & DOI: 10.21 I 06 /ijma.325 \\
\hline
\end{tabular}

ORIGINALARTICLE

\title{
A Comparison of Placental Alpha Microglobuliun-I Rapid Immunoassay and Standard Clinical Method For Diagnosis of Premature Rupture of Membranes
}

\author{
Idowu O Adebara, MBBS, MPH, FMCOG;',2® Damilola Ifarinola, MBBS, FWACS;' \\ Olumide Adewara, MBBS, FWACS;,2 Adebayo Adeniyi, MBBS, FMCOG;,2 Ayobami O. Oni, MBBS, FMCOG;' \\ Gabriel Alayode, MBBS, FMCP; ${ }^{2,3}$ Olusegun Busari, MBBS, FMCP;2,4 Kolawole Fasakin, PhD ${ }^{5}$ \\ 'Department of Obstetrics \& Gynaecology, Federal Teaching Hospital, Ido Ekiti; ${ }^{2}$ College of Health Sciences, Afe Babalola University, Ado Ekiti, Nigeria; \\ ${ }^{3}$ Department of Internal Medicine, Federal Teaching Hospital, Ido Ekiti, Nigeria; ${ }^{4}$ Department of Internal Medicine, Federal Teaching Hospital, Ido Ekiti, \\ Nigeria; ${ }^{5}$ Department of Haematology \& Blood Transfusion Services, Federal Teaching Hospital, Ido Ekiti, Nigeria. \\ Corresponding author email: adebaraio@abuad.edu.ng
}

\begin{abstract}
Background/Objective: Premature rupture of membranes (PROM) poses significant risk to the wellbeing of a pregnant woman and her fetus; the risk is more when not appropriately diagnosed and managed. The search for accuracy and increased specificity in diagnosis of PROM is an on-going process. The purpose of this study was to determine the accuracy of placental alpha microglobulin-I (AmniSure $R O M()$ based test in detecting presence of amniotic fluid in cervico-vaginal secretions compared with standard clinical assessment in diagnosis of PROM in a rural tertiary hospital in South West, Nigeria. AmniSure ROM is a point of care test which is convenient to both the health care provider and patient; thus its use can shorten the turnaround time and improve patient care.
\end{abstract}

Methodology: This was a cross-sectional study. All pregnant women with symptoms suggestive of PROM premature over a period of six months at the Federal Teaching Hospital, Ido Ekiti, south-west Nigeria, were recruited and evaluated using the standard clinical evaluation and AmniSure ROM®.

Results: In all, 64 participants were recruited. Mean maternal age and gestational age at presentation were 29.6 \pm 3.4 years and $37.2 \pm 2.4$ weeks respectively. AmniSure ROMR test was positive in $81.2 \%$ of the participants, while standard clinical test was positive in $71.9 \%$ of the participants. The two tests were positive in $70.3 \%$ of all evaluated participants. The sensitivity of AmniSure ROM in diagnosis of PROM was $97.8 \%$ compared to that obtained in standard clinical assessment. The negative predictive value of AmniSure ROM was $91.7 \%$

Conclusion and Global Health Implications: Compared to standard clinical assessment, AmniSure ROM test was a more sensitive, rapid and accurate method for confirming the diagnosis of rupture of membrane. Its adoption in routine practice will reduce complications associated with delay and missed diagnosis following use of routine standard clinical assessment alone.

Key words: Placental • Alpha macroglobulin-I • Rapid immunoassay • Clinical method • Premature rupture of membranes

Copyright @ 2019 Adebara et al.This is an open-access article distributed under the terms of the Creative Commons Attribution License, which permits unrestricted use, distribution, and reproduction in any medium, provided the original work is properly cited. 


\section{Introduction}

Premature rupture of membranes (PROM) is defined as spontaneous rupture of fetal membranes before the onset of labor in a viable gestation., ${ }^{1,2}$ Approximately, $8 \%$ to $10 \%$ of term pregnancies will experience spontaneous ROM prior to the onset of uterine activity. ${ }^{1-4}$ Preterm premature rupture of membranes (PPROM) complicates $2 \%$ to $4 \%$ of all singleton and $7 \%$ to $20 \%$ of twin pregnancies; ${ }^{1-5}$ a prevalence rate of $1.3 \%$ was found by researchers in Maiduguri, ${ }^{6} 3.3 \%$ in Enugu ${ }^{7}$ and a higher value of $6.8 \%$ was reported in Lome, Togo. ${ }^{8}$ PROM is associated with preterm delivery which continues to be a major contributor to perinatal mortality in Nigeria and in other low and middle income countries (LMIC); it occurs in $25 \%-30 \%$ of all preterm births, and accounts for $18 \%-20 \%$ of prenatal deaths in the United States. ${ }^{1-5,9}$ PROM has been linked with increased maternal morbidity and mortality, accounting for as high as $20 \%$ maternal deaths from a series in Eastern Nigeria. ${ }^{7}$ An accurate diagnosis of ROM is important in the management of ROM especially in preterm gestation. Failure to ascertain the correct diagnosis would result in either failure to initiate proper treatment with its attendant risks or would lead to unnecessary interventions such as hospitalization and inappropriate use of antibiotics and antenatal corticosteroids, as well as misapplied induction of labor. ${ }^{10}$ Previous study on global burden of PROM showed that nearly a third of all preterm births were due to $\mathrm{PROM}^{8}$ while approximately $70 \%$ of all cases of PROM occur in pregnancies at term. In referral centers, up to $50 \%$ of PROM may occur in preterm. Incidence of PROM ranges from 5-10\% of all deliveries worldwide, " and PROM occurs in approximately $3.0 \%$ of all pregnancies and the cause of a third of all preterm births. Accurate diagnosis of PROM is fraught with challenges because there are other clinical conditions that present with drainage of fluid par vaginam during pregnancy other than ROM, including urinary incontinence, leukorrhea of pregnancy, and some vaginal infections.

For generations, practitioners have sought for a test that is highly sensitive and specific in the diagnosis of ROM. The standard clinical diagnosis of premature ROM is by visually ascertaining egress of fluid from the cervical Os and or pooling of fluid in the posterior fornix at a sterile speculum examination; this procedure is non-specific particularly in low resource settings because of the lack of capacity for specific identification of the fluid as amniotic fluid. ${ }^{12-16}$ Identifying a fluid as amniotic in many developing countries over the years utilized its characteristic properties but these do not provide the desired degree of specificity, precision and accuracy. The desire to increase the accuracy, sensitivity and specificity in diagnosis has been the driving force behind many intellectual discourses and research studies over the years to identify substances in amniotic fluid and properties of amniotic fluid that could differentiate it from other differentials. ${ }^{13,14}$ A test is said to be $100 \%$ sensitive if it can identify all those who truly have the disease. Specificity of a test refers to the ability of the screening test to be able to accurately identify those without the disease condition, the higher the specificity of a test, the more reliable it is in screening. Diagnostic methods using nitrazine paper and determination of ferning/ arborization have sensitivities approaching up to $90 \%$. The $\mathrm{pH}$ of vaginal secretions is generally 4.5 to 6.0 , whereas amniotic fluid usually has a $\mathrm{pH}$ of 7.1 to

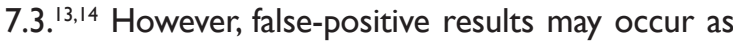
the result of contamination with blood, urine, semen, alkaline, antiseptics, or secretion from bacterial vaginosis and false-negative results can occur with prolonged leakage and minimal residual fluid.

Placental alpha macroglobulin-I(PAMG-I) is a protein marker that was isolated by $D$ Petrunin in 1975 from amniotic fluid and was originally referred to as specific alpha I globulin of placenta and is present in amniotic fluid in all semesters of pregnancy. ${ }^{17,18}$ Concentration of PAMG-I in cervical and vaginal secretions of pregnant women without complications ranges from 0.05 and $0.22 \mathrm{ng} / \mathrm{mL}$, while its concentrations in the amniotic fluid is between 2,000 and $25,000 \mathrm{ng} / \mathrm{mL}^{15}$ This sharp difference is an important factor that can suggest presence of amniotic fluid and hence rupture of fetal membranes. The AmniSure ROM test is a rapid, noninstrumented qualitative immunochromatographic test for in-vitro detection of amniotic fluid in vaginal secretion of pregnant women, the test detects 
PAMG-I in vaginal secretions and is intended to aid in the detection of ROM in pregnant women greater than 34 weeks gestation with signs, symptoms or complaints suggestive of rupture of membranes. ${ }^{17,18}$ In a prospective observational study performed in patients with signs or symptoms of rupture of membranes at Seoul National University Hospital, Korea, rupture of membranes was diagnosed at initial presentation in $76 \%$ using standard clinical assessment and $88 \%$ using PAMG-I immunoassay. ${ }^{18}$ Higher accuracies were recorded by other authors, ${ }^{19}$ but there is a virtual lack of data on the diagnostic accuracy of PAMG-I in Ekiti state and in our clinical setting. Diagnosis of ruptured fetal membranes is of crucial importance at any period in a pregnancy for prompt, timely and proper treatment. While standard clinical assessment is accurate, the procedure could be cumbersome and requires training for it to be performed accurately. Conversely, the AmniSure test is a rapid, non-instrumented test; it is a qualitative test that is easy to perform, and result is not affected by the common causes of confusion in diagnosing ROM. PAMG-I based test such as AmniSure can be deployed at the lower levels of health care in low resource settings, where the larger obstetrics population receive medical care to improve diagnosis rate. In many health care facilities in low resource settings, the skills required to perform the standard clinical assessments are not readily available and adequate. While AmniSure test is not affected by requirements for sterile equipment and need for autoclaving, a major drawback to its use in low resource settings may be the high costs and availability where it may be most needed.

\section{I. Objectives of the Study}

This study aim was to determine the accuracy of placental alpha macroglobulin-I (AmniSure ROM) in diagnosing the presence of amniotic fluid in cervico-vaginal secretion in suspected rupture of fetal membranes compared with standard clinical examination.

\section{Methods}

This was a prospective cross sectional study involving 64 pregnant women who met the eligibility criteria and presented at the emergency unit and antenatal clinic (ANC) of Federal Teaching Hospital Ido Ekiti. The required sample size was determined using the Fisher's statistical formula. ${ }^{20}$ From a previous study conducted in a teaching hospital at another center in South-West Nigeria, the prevalence of premature rupture of membranes $(\mathrm{P})$ was $3.9 \%{ }^{21}$

$$
\text { Therefore, } \begin{aligned}
\mathrm{n} & =\frac{(1.96)^{2} \times 0.039(1-0.039)}{0.05^{2}} \\
& =57.59(\text { approximately } 58) .
\end{aligned}
$$

The women were evaluated for ROM with a detailed history, physical examination and a sterile speculum examination. All the recruited participants had standard clinical assessment protocol, which was the standard for diagnosis of ROM at the hospital, the AmniSure test was performed immediately thereafter by the same examiner. The evaluation procedure was carried out by trained clinical assistants (all were post part I residents in the department of obstetrics and gynaecology). A structured questionnaire was designed and used to collect relevant data on sociodemographic status of the participants; other data obtained were last menstrual period, past obstetric history, history past and present vaginal discharge. The procedure was explained to the patient and consent was obtained. The patient thereafter had a sterile speculum vaginal examination. Standard clinical assessment of leakage or egress of amniotic fluid from the cervical Os and/or pooling of amniotic fluid was done by direct visualisation of the cervical os during the procedure of sterile speculum examination of the patient and when present were interpreted as positive for standard clinical assessment. The findings during sterile speculum examination were recorded on the study proforma. PAMG-I immunoassay using the AmniSure international kit according to the manufacturer's instructions ${ }^{22}$ was also done and the findings recorded in the structured questionnaires to enable entry of study demographic and analytical data. The kits used were obtained from AmniSure International LLC (30 JFK Street, $4^{\text {th }}$ Floor, Cambridge). ${ }^{22}$ Management of patients recruited for this study were based strictly on the findings of standard clinical assessment during sterile speculum examination as it is the usual practice in the hospital. Ethical clearance for this study was obtained from 
Table I: Socio-demographic characteristics of the participants at presentation

\begin{tabular}{lc}
\hline Variables & Frequency (\%) \\
\hline Age (years) & $6(9.4)$ \\
\hline $20-24$ & $26(40.6)$ \\
\hline $25-29$ & $27(42.2)$ \\
\hline $30-34$ & $5(7.8)$ \\
\hline$\geq 35$ & $29.6 \pm 3.4$ \\
\hline Mean \pm SD & $29.5(23.0-37.0)$ \\
\hline Median (Range) & \\
\hline Occupation & $6(9.4)$ \\
\hline Housewife & $14(21.9)$ \\
\hline Unskilled worker & $5(7.8)$ \\
\hline Semi - Skilled worker & $23(35.9)$ \\
\hline SkilledWorker & $8(12.5)$ \\
\hline Professional & $8(12.5)$ \\
\hline Unemployed & \\
\hline Religion & $47(73.4)$ \\
\hline Christianity & $17(26.6)$ \\
\hline Islam & \\
\hline Educational Status & $4(6.3)$ \\
\hline Primary/Arabic & $17(26.6)$ \\
\hline Secondary & $14(21.9)$ \\
\hline Teacher Training College & $29(45.3)$ \\
\hline Polytechnic/University & \\
\hline Marital Status & $60(93.2)$ \\
\hline Co - Habiting & \\
\hline Married & \\
\hline & \\
\hline
\end{tabular}

the ethical review board of the Federal Teaching Hospital Ido Ekiti.

\section{Results}

Table I shows the socio-demographic characteristics of study participants while table 2 shows the clinical data of participants on admission. The estimated gestational age at presentation ranged from 28.7 -41.9 weeks; mean was $37.2 \pm 2.4$ weeks; and the commonest complaint at presentation was trickling of fluid par vaginam. Egress of fluid from the cervix was confirmed during sterile speculum examination in forty-six (7I.9\%) of the participants. The amniotic fluid index of participants on ultrasound ranged from 4-I4.I (normal range=) with a mean value of $9.5 \pm 2$.I.
Table 2: Clinical data of participants on admission

\begin{tabular}{lc}
\hline $\mathbf{N}-\mathbf{6 4}$ & \\
\hline Variable & Frequency (\%) \\
\hline Gravidity & $6(9.4)$ \\
\hline Primigravidae & $58(90.6)$ \\
\hline Multigravidae & $3.0 \pm 1.4$ \\
\hline Mean \pm SD & $3.0(1.0-8.0)$ \\
\hline Median (Range) & $1.3 \pm 1.3$ \\
\hline Parity & $1.0(0.0-5.0)$ \\
\hline Mean $\pm S D$ & \\
\hline Median (Range) & $1.2 \pm 1.0$ \\
\hline Mean $\pm S D$ & $1.0(0.0-4.0)$ \\
\hline Median (Range)
\end{tabular}

Estimated Gestational Age at Presentation (weeks)

\begin{tabular}{lc}
\hline $25-33$ weeks & $4(6.3)$ \\
\hline $34-36$ weeks & $18(28.1)$ \\
\hline$>-37$ weeks & $42(65.6)$ \\
\hline Mean \pm SD & $37.2 \pm 2.4$ \\
\hline Median (Range) & $37.3(28.7-41.9)$ \\
\hline Duration of Symptoms (Hours) & $20.3 \pm 53.0$ \\
\hline Mean \pm SD & $5.5(2.0-384.0)$ \\
\hline Median (Range) & $37(57.8)$ \\
\hline History of Draining & $27(42.2)$ \\
\hline Trickling par vaginam & \\
\hline $\begin{array}{l}\text { Gush of fluid Par } \\
\text { Vaginam }\end{array}$ & \\
\hline Colour of fluid & $54(844)$ \\
\hline
\end{tabular}

\begin{tabular}{lc}
\hline Colourless & $54(84.4)$ \\
\hline Whitish & $3(4.7)$ \\
\hline Yellowish & $7(10.9)$ \\
\hline
\end{tabular}

Egress from the cervix on sterile speculum exam

\begin{tabular}{ll}
\hline Yes & $46(71.9)$ \\
\hline No & $18(28.1)$ \\
\hline
\end{tabular}

Pooling in the posterior fornix

\begin{tabular}{ll}
\hline Yes & $52(81.2)$ \\
\hline No & $12(18.8)$
\end{tabular}

\begin{tabular}{lc}
\hline Ultrasound Findings & \\
\hline Oligohydramnios & $10(15.6)$ \\
\hline Normohydramnios & $54(84.4)$ \\
\hline Ultrasound Amniotic fluid Index & \\
\hline Mean \pm SD & $9.5 \pm 2.1$ \\
\hline Median (Range) & $9.6(4.0-14.1)$ \\
\hline
\end{tabular}


Figure I shows the result of findings following the standard clinical assessment and the AmniSure test. Fifty-two (8I.2\%) out of the 64 participants recruited had positive AmniSure tests, while 46 (7I.9\%) out the 64 recruited had positive results following standard clinical assessment. Table 3 compares the result of standard clinical assessment with AmniSure test. In all, 45 (70.3\%) participants had positive test results using both diagnostic methods; II (I7.2\%) participants had negative results for both tests. Only one participant with a positive result following standard clinical assessment had negative result following the AmniSure test; $\mathrm{p}$-value was less than $0.00 \mathrm{I}^{\mathrm{F}}$ and $0.035^{\mathrm{F}}$ both of which imply a statistically significant

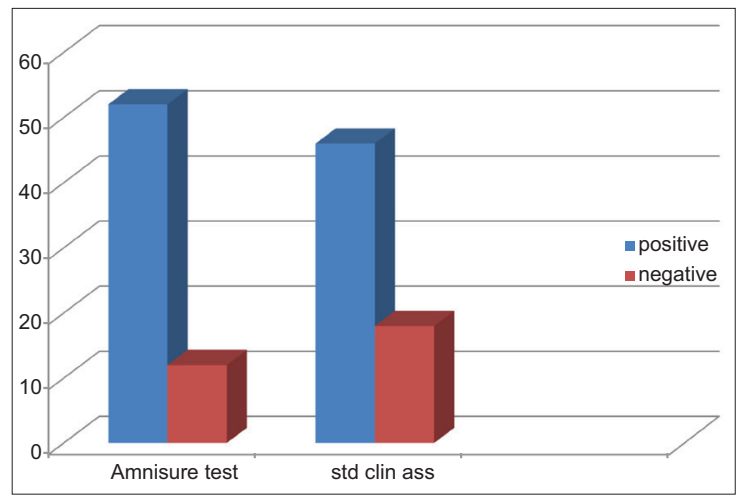

Figure I: Standard clinical assessment and AmniSure test of pregnant women with history of amniotic fluid draining difference between the AmniSure test and the standard clinical assessment.

\section{Discussion}

This study compared the results of findings following evaluation of participants with history suggestive of premature ROM using the standard clinical assessment at Federal Teaching Hospital, Ido Ekiti, and the AmniSure ROM test. Of the 64 participants that were evaluated, ROM was detected in 46 (7I.9\%) participants using the standard clinical assessment while the AmniSure test strip detected ROM in 52 (8I.2\%) study participants. The distinction between the two diagnostic modalities was obvious.

The findings of our study were similar to findings by Lee et al. in which $76 \%$ of his subjects had ROM diagnosed at initial presentation using standard clinical assessment and $85 \%$ using placental alphamicroglobulin-I immunoassay. ${ }^{18}$ According to Lee et al. ${ }^{18}$ using longitudinal assessment as the clinical gold standard, placental alpha-microglobulin-I immunoassay confirmed ROM at initial presentation with a sensitivity of $98.7 \%$ and specificity of $87.5 \%$, a positive predictive value of $98.1 \%$ and negative predictive value of $91.3 \%$. The sensitivity of the AmniSure strip was $97.8 \%$ against the $84.3 \%$ observed following the usual clinical assessment at the hospital. The specificity was $61.1 \%$ and positive predictive value was $86.5 \%$ for the AmniSure test, while the

Table 3: Comparing the result of standard clinical assessment with AmniSure test

\begin{tabular}{lccccc}
\hline \multirow{2}{*}{ AmniSure test } & \multicolumn{2}{c}{ Standard Clinical Assessment } & Total & X & P-value \\
\cline { 2 - 5 } & Positive & Negative & & & \\
\hline Positive & 45 & 7 & 52 & 25.757 & $<0.00 I^{\mathrm{F}}$ \\
\hline Negative & $\mathrm{I}$ & $\mathrm{II}$ & 12 & \\
Total & 46 & 18 & 64 & $0.035^{\S}$ \\
\hline
\end{tabular}

F = Fisher's Exact Test; $\S=$ McNemar Test

Table 4: AmniSuretests results

\begin{tabular}{lc}
\hline True positive for AmniSure test=45 & True negative for AmniSure test=I I \\
\hline False positive for AmniSure test=7 & False negative for AmniSure test=I \\
\hline Sensitivity=True positive AmniSure/all with positive standard clinical assessment $\times 100=45 / 46 \times 100=97.8 \%$. \\
\hline Specificity=True negative AmniSure/all with negative standard clinical assessment $\times 100=1 \mathrm{I} / 18 \times 100=61.1 \%$. \\
\hline Positive predictive value=True positive AmniSure/all positive AmniSure $\times 100=45 / 52 \times 100=86.5 \%$. \\
\hline Negative predictive value=True negative AmniSure test/all negative AmniSure test $\times 100=1 \mathrm{I} / 12 \times 100=91.7 \%$. \\
\hline
\end{tabular}


negative predictive value was $91.7 \%$ (Table 4). There was a statistically significant difference in the diagnosis of PROM between the AmniSure assessment and the standard clinical assessment.

The sensitivity and specificity of AmniSure in this study were a little different to the findings reported by Cousins et al. ${ }^{17}$ after evaluation of 203 symptomatic women who presented with complaints suggestive of rupture of membranes. According to Cousins et al., ${ }^{17}$ the AmniSure had a sensitivity of $98.9 \%$, specificity of $100 \%$, positive predictive value of $100 \%$ and negative predictive value of $99.1 \%$. Similar study by Agbara et al. ${ }^{19}$ showed that Amnisure had $97.7 \%$ sensitivity, $100 \%$ specificity and positive predictive values, and $96.7 \%$ negative predictive values. The statistical analysis shows that the Amnisure test was more sensitive and more predictive in the diagnosis of ROM compared with the standard clinical test at the Federal Teaching Hospital Ido Ekiti although the specificity is not as high as some other studies had found. ${ }^{23-27}$ The cause of the lower specificity of AmniSure test in this study compared to findings by other researchers remained unknown and may require further review in future studies. The findings in this study provide further evidence that there is a need to review standard of practice in developing countries where diagnosis of PROM is based on use of direct visualization of amniotic fluid drainage from the external cervical Os at sterile speculum examination, rather than a simpler test like PAMGI based tests. These tests are still not widely employed in the diagnosis of PROM in our hospital center. Future efforts should focus on the diagnosis of PROM in resource constrained settings like the Federal Teaching Hospital, Ido Ekiti, Nigeria and other LMIC.

\section{Conclusion and global health implications}

Findings at this Federal Teaching Hospital in South West Nigeria show that AmniSure ROM is more sensitive and more specific than the standard clinical assessment in the diagnosis of ROM.Although standard clinical assessment has stood the test of time, there is a need to adopt an easier and less cumbersome test. This important given the global call for universal health coverage. The deployment of PAMG-I based test will no doubt increase access to an improved obstetric care devoid of undue intrusive intervention.

\section{Compliance With Ethical Standards}

Conflicts of Interest: No conflicts of interest. Financial Disclosure: None. Funding/Support: None. Ethics Approval: Ethical approval was obtained from Institution Human Reseach and Ethical committee.

\section{Key Messages}

Premature rupture of membrane (PROM) is a significant contributor to perinatal and maternal mortality in developing countries.

- Early and accurate diagnosis is essential in preventing the unfortunate but avoidable outcomes due to PROM.

- Placental alpha macro-globulin-based test is a more sensitive and easy-to-perform test compared to standard clinical test in the diagnosis of PROM; its wide deployment in developing countries will undoubtedly contribute to reducing maternal mortality.

\section{References}

I. ACOG Committee on Practice Bulletins-Obstetrics, authors. Clinical management guidelines for obstetrician-gynecologists. (ACOG Practice Bulletin No. 80: premature rupture of membranes). Obstet Gynecol. 2007; 109: 1007-1019.

2. Caughey AB, Robinson JN, Norwitz ER. Contemporary diagnosis and management of preterm premature rupture of membranes. Rev Obstet Gynecol. 2008; I: I I-22.

3. Alexander JM, Cox SM. Clinical course of premature rupture of the membranes. Semin. Perinat. 1996; 20: 369-374.

4. Odunsi A, Odutayo R. Premature rupture of fetal membranes. In: Okonofua F, Odunsi K (eds). Contemporary Obstetrics and Gynaecology for Developing Countries. Benin City: Women's Health and Action Research Centre. 2003; 430-453.

5. Kwawukume, EY. Premature rupture of membranes. In: EY Kwawukume, EE Emuveyan (eds.). Comprehensive Obstetrics in the Tropics. 2002; I5 I-I 56. 
6. Idrisa A, Pius S, Bukar M. Maternal and neonatal outcomes in premature rupture of membranes at Maiduguri Teaching Hospital. Maiduguri, NorthEastern Nigeria. Trop J Obstel Gynaecol. 2019; 36(I): I5-20.

7. Okeke TC, Enwereji JO, Okoro OS, Adiri CO, Ezugwu EC, and Agu PU. The Incidence and Management Outcome of Preterm Premature Rupture of Membranes (PPROM) in a Tertiary Hospital in Nigeria. Amer J Clin Med. Research. 20I4; 2(1): 14-17.

8. Mounerou Salou, Fiali Lack, Amah Biova AdamaHondegla, Sika Dossim, Novissi Tsogbale, Adama Gbadoe, Koffi Akpadza, Mireille Prince-David. Premature Rupture of the membranes at the Sylvan Olympio University Hospital of Lome, Togo: Microbiological and Outcomes. Amer J Infect Dis and Microbiol. 20I5; 3(6): I52-I56.

9. Mokuolu, OA, Suleiman, B.,Adesiyun, O., \& Adeniyi,A. Prevalence and determinants of pre-term deliveries in the University of llorin Teaching Hospital, llorin, Nigeria. Pediatric Reports, 20 10; 2(I): e3. doi: 10.408I/ pr.20I0.e3

10. Kurioglu YS, Bildircin FD, Karl P, Ozdemir. Use of vaginal creatinine levels in detecting premature rupture of membranes. J Surg and Med. 2019; 3(6):42I-427.

II. Assefa NE, Berhe H, Girma F, Berhe K, Berhe YZ, Gebreheat G,WeridWM, Berhe A, Rufae HB,Welu G. Risk factors of premature rupture of membranes in public hospitals at Mekele city, Tigray, a case control study. BMC Preg and Childbirth. 2018; 18:386-392.

12. Duff P. Premature rupture of the membranes in term patients. Semin Perinatol. 1996; 20: 40 I-408.

13. Duff P. Premature rupture of membranes at term. N Eng.J Med. 1996; 334(16): 1053-1054.

14. Mercer BM, Goldenberg RL, Meis PJ, et al. The Preterm Prediction Study: prediction of preterm premature rupture of membranes through clinical findings and ancillary testing. The National Institute of Child Health and Human Development Maternal-Fetal Medicine Units Network. Am J Obstet Gynecol. 2000; 183: 738-745.

15. El-Messidi A, Cameron A. Diagnosis of premature rupture of membranes: inspiration from the past and insights for the future. J Obstet Gynaecol Can. 2010; 32: $56 \mid-569$.

16. Yamada H, Fujimoto S. Rapid diagnosis of premature rupture of membranes using a new kit employing anti-AFP monoclonal antibody. Arch Gynecol Obstet. 1995; 256: 57-61.

17. Cousins LM, Smok DP, Lovett SM, Poeltler DM. AmniSure placental alpha microglobulin-I rapid immunoassay versus standard diagnostic methods for detection of rupture of membranes. Am J Perinatol. 2005; 22: 317-320.

18. Lee SE, Park JS, Norwitz ER, Kim KW, Park HS, Jun JK. Measurement of placenta alpha microglobulin-I in cervico-vaginal discharge to diagnose rupture of membranes. Obstet Gynaecol. 2007; 109(3): 634-40.

19. Agbara JO, Fabamwo AO, Oshodi YA. Diagnosis of foetal membrane ruptures: Placenta alpha macroglobulin-I to the rescue. Trop. J Obstet and Gynaecol. 20I7; 34(2): 84-90.

20. Fisher A.A, Laing J.E, Stoeckel J.E, Townsend J.W. Handbook for Family Planning Operations Research Design. New York: Population Council, 1998.

21. Adeniji OA, Atanda OOA, Interventions and neonatal outcomes in patients with premature rupture of fetal membranes at and beyond 34 weeks gestation at a tertiary heath facility in Nigeria. Br. J. Med. Medical Res. 2013;3(4): I388-1 397.

22. AmniSure ROM test instruction. Available at www. qiagen.com

23. Phupong V, Sonthirathi V. Placental alpha microglobulin-I rapid immunoassay for detection of premature rupture of membranes. J Obstet Gynaecol Res. 20I2; 38(I): 226-230.

24. Eleje UG, lgwegbe OA, lkechebelu IJ et al. Accuracy and cost analysis of placenta alpha-microglobulin-I test in the diagnosis of premature rupture of fetal membranes in resources limited community settings. J Obstet Gynaecol. Res. 20 I4; 4 I (I): 29-38.

25. Abdelazim IA, Makhlouf $\mathrm{HH}$. Placental alpha microglobulin-I (Amnisure test) for detection of premature rupture of fetal membranes. Arch Gynecol Obstet. 201 2; 285(4): 985-989.

26. Birkenmaier A, Ries JJ, Kuhle J, et al. Placental alpha microglobulin-I to detect uncertain rupture of membrane in a European cohort of pregnancies. Arch Gynecol Obstet. 20 I 2; 285(I): 21-25.

27. Marcellin L, Anselem O, Guibourdenche J, et al. Comparison of two bedside tests performed on cervicovaginal fluid to diagnose premature rupture of membranes. J Gynecol Obstet Biol Reprod (Paris). 20I I; 40(7):65I-656.

๑ 2019 Global Health and Education Projects, Inc. 